\title{
Pengaruh Promosi Kesehatan Terhadap Pengetahuan Ibu Tentang Pemberian Makanan Pendamping ASI (MP-ASI) Di Puskesmas Alusi Kecamatan Kormomolin Kepulauan Tanimbar Maluku Tahun 2019
}

\author{
Milla Evelianti Saputri*, Dwi Rohyani, Jacoba Batlajery \\ Fakultas Ilmu Kesehatan, Universitas Nasional, Jakarta, Indonesia \\ Corresponding author: Milla Evelianti Saputri (milla.evelianti@civitas.unas.ac.id) \\ Received: Mei, 20 2020; Accepted: June, 28 2020; Published: September, 12020
}

\begin{abstract}
ABSTRAK
MP-ASI adalah makanan atau minuman yang mengandung gizi diberikan kepada bayi atau anak untuk memenuhi kebutuhan gizinya, Penelitian WHO (2011), menyatakan bahwa hanya $40 \%$ bayi di dunia yang mendapatkan ASI eksklusif sedangkan $60 \%$ bayi lainnya ternyata telah mendapatkan MP-ASI saat usianya kurang dari 6 bulan. Desain penelitian yang digunakan adalah one group pretest post test design. Tehnik pengambilan sampel menggunakan total populasi dengan jumlah 20 . Nilai rata-rata pengetahuan responden tentang pemberian makanan pendamping ASI sebelum diberikan promosi kesehatan 43,75, sementara rata-rata pengetahuan responden sesudah diberikan promosi kesehatan meningkat menjadi 62,75. ada pengaruh promkes terhadap peningkatan pengetahuan ibu tentang pemberian MP ASI di Puskesmas Alusi Kecamatan Kormomolin Kepualaua Tanimbar Maluku. Kegiatan promosi kesehatan sangat penting untuk meningkatkan pengetahuan ibu terhadap pemberian makanan pendamping ASI (MP-ASI).
\end{abstract}

Kata Kunci: Promosi Kesehatan, Pengetahuan, MP-ASI

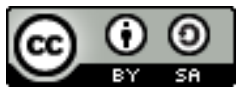

This is an open-acces article distributed under the terms of the Creative Commons Attribution-ShareAlike 4.0 International License.

\section{PENDAHULUAN}

Masa balita merupakan masa yang penting dalam pertumbuhan fisik maupun perkembangan struktur, fungsi tubuh, emosi, intelektual, serta tingkah laku. Pertumbuhan dipengaruhi oleh banyak faktor seperti keturunan, makanan, kesehatan, dan lingkungan yang baik. Pemberian ASI dan makanan pendamping ASI (MP-ASI) yang tepat dan benar merupakan salah satu upaya prioritas dalam mengembangkan kualitas sumber daya manusia, menurut hasil penelitian khasanah (2016) bahwa waktu pertama pemberian MP-ASI berhubungan signifikan dengan kejadian stanting. Pemberian MP-ASI sebelum anak berumur enam bulan tidak dianjurkan, karena dapat meningkatkan kemungkinan terkontaminasi dan meningkatkan risiko terkena penyakit, khususnya diare, sedangakn menurut hasil penelitian Mahardika (2018) dalam pemberian MP-ASI pertama kali dengan status gizi pada anak usia 612 bulan tidak memiliki hubungan yang signifikan, dan menurut hasil penelitian Afriyani (2016), Faktor-faktor yang mempengaruhi pemberian MP-ASI pada Usia 0-6 Bulan adalah 
dukungan keluarga, pendidikan, pendapatan, dan tradisi semua memiliki hubungan yang signifikan dengan nilai $\mathrm{P}<0,05$, hasil penelitian bahwa hanya $40 \%$ bayi di dunia yang mendapatkan ASI eksklusif sedangkan $60 \%$ bayi lainnya ternyata telah mendapatkan MP-ASI saat usianya kurang dari 6 bulan. Data tersebut masih sangat mengkhawatirkan, selaras dengan dengan hasil penelitian Eriza (2016) bahwa dari kedua variabel yang diteliti pengetahuan dan pekerjaan yang memiliki hubungan terhadap pemberian MP-ASI adalah faktor pengetahuan dengan nilai $\mathrm{P}=0,0003$ sehingga perlu diupayakan dalam meningkatkan pengetahuan ibu, dengan melakukan kegiatan penyuluhan kesehatan untuk meningkatkan pengetahuan dan sikap tentang kesehatan yang diperlukan oleh masyarakat sehingga akan memudahkan terjadinya perilaku sehat pada mereka.. menurut Riset Kesehatan Dasar (Rikesdas) propinsi Maluku usia 0-23 bulan menurut status gizi dengan indeks berat badan per umur tahun 2016 gizi buruk $4,91 \%$, gizi kurang 14,39\%,gizi baik 78,84\%, gizi lebih 1,85\%. Sedangkan pada tahun 2017 gizi buruk $4,70 \%$, gizi kurang $13,80 \%$, gizi baik $78,50 \%$, gizi lebih $2,90 \%$.

\section{METODE}

Jenis penelitian ini adalah pra-eksperimen dengan menggunakan desain penelitian adalah one group pretest post test design. yang bertujaun untuk melihat apakah ada pengaruh promosi kesehatan teradap pengetahuan Ibu tentang Pemberian Makan Pendamping ASI pada Ibu di Puskesmas Alusi Kecamatan Kormomolin Kepulauan Tanimbar Maluku.

Rancangan Penelitian: penelitian ini, data yang digunakan adalah data primer, peneliti akan meminta ijin penelitian kepada pihak Puskesmas Alusi, selanjutnya peneliti akan mengadakan pendekatan kepada calon responden untuk memberikan penjelasan dan membuat kesepakatan bahwa calon responden bersedia menjadi responden. Responden yang bersedia mengikuti kegiatan promkes.

Responden terlebih dahulu akan diberikan inform consent dengan diberikan penjelasan mengenai informasi dasar dan prosedur yang akan dilakukan selama penelitian berlangsung. Responden berhak untuk mengundurkan diri tanpa ada sangsi yang diberikan.

\section{HASIL}

Analisis univariat terhadap masing-masing variabel ditampilkan dalam bentuk table distribusi frekuensi. Hasil analisis univariat yang diperoleh adalah sebagai berikut:

Tabel 1.1 Distribusi Frekuensi karakteristik responden berdasarkan umur di Wilayah Kerja Puskesmas Alusi Tahun 2019.

\begin{tabular}{ccc}
\hline Umur (tahun) & $\mathbf{n}$ & \% \\
\hline $20-$ & 17 & 85 \\
35 & 3 & 15 \\
$>35$ & 3 & $\mathbf{1 0 0}$ \\
\hline Total & $\mathbf{2 0}$ & \\
\hline
\end{tabular}

penelitian pada tabel 1.1 menunjukkan responden terbanyak dengan umur 20-35 tahun sebanyak 17 responden (85\%) dan distribusi terkecil adalah kelompok umur lebih dari 35 tahun sebanyak 3 responden (15\%). 
Tabel 1.2 Distribusi karakteristik responden berdasarkan Pendidikan di Wilayah Kerja Puskesmas Alusi Tahun 2019.

\begin{tabular}{lcc}
\hline Pendidikan & n & \% \\
\hline SD & 3 & 15 \\
SMP & 10 & 50 \\
SMA & 5 & 25 \\
S1 & 2 & 10 \\
\hline TOTAL & $\mathbf{2 0}$ & $\mathbf{1 0 0}$ \\
\hline
\end{tabular}

Berdasarkan hasil penelitian pada tabel 1.2 menunjukkan data bahwa responden terbanyak dengan pendidikan terakhir SMP sebanyak 10 responden $(50 \%)$, pendidikan terakhir SMA sebanyak 5 reponden (25\%), pendidikan terakhir SD sebanyak 3 responden (15\%) dan pendidikan terakhir S1 sebanyak 2 responden (10\%)

Tabel 1.3 Distribusi karakteristik responden berdasarkan Pekerjaan di Wilayah Kerja Puskesmas Alusi Tahun 2019.

\begin{tabular}{lcc}
\hline Pekerjaan & $\mathrm{n}$ & $\%$ \\
\hline Tidak bekerja & 19 & 95 \\
Bekerja (PNS) & 1 & 5 \\
\hline Total & $\mathbf{2 0}$ & $\mathbf{1 0 0}$ \\
\hline
\end{tabular}

Berdasarkan hasil penelitian pada tabel 4.3 menunjukkan responden berdasarkan pekerjaan terbanyak yaitu responden yang tidak bekerja sebanyak 19 responden (95\%) sedangkan responden yang bekerja hanya 1 responden $(5 \%)$

Tabel 1.4 Distribusi Frekuensi rata-rata pengetahuan ibu sebelum dan sesudah diberikan promosi kesehatan

\begin{tabular}{lllllll}
\hline Variabel & $\mathrm{N}$ & Min & Max & SE & SD & Mean \\
\hline Pre test & 20 & 25 & 55 & 512 & 8.091 & 43.75 \\
\hline Pre test & 20 & 45 & 80 & 512 & 8.656 & 62.75 \\
\hline
\end{tabular}

Berdasarkan tabel $1.4 \mathrm{i}$ di dapatkan bahwa tingkat pengetahuan responden sebelum diberikan promosi kesehatan rata-rata memperoleh nilai 43.75, dengan nilai terendah 25 dan tertinggi 55 . Sedangkan tingkat pengetahuan responden setelah diberikan promosi kesehatan rata-rata memperoleh nilai 62.75, dengan nilai terendah 45 dan tertinggi 80 .

Tabel 1.5 Pengaruh Promosi Kesehatan terhadap pengetahuan ibu tentang pemberian makanan pendamping asi (MP ASI

\begin{tabular}{lllll}
\hline Variabel & SE & SD & Mean & Sig \\
\hline Promosi Kesehatan Pre test & & & & \\
& 1.809 & 8.091 & 43.75 & 0.000 \\
Post test & 1.936 & 8.656 & 62.75 & 0.000
\end{tabular}

Berdasarkan tabel 4.5 sebelum melakukan pengaruh promosi kesehatan terhadap pengetahuan 
ibu tentang pemberian MP ASI yaitu std. Error of skewness yaitu 1.809, Std. Deviation 8.091, Signifikan hasil 0.000. Sedangkan pengaruh setelah di berikan promosi kesehatan terhadap pengetahuan ibu tentang pemberian MP ASI yaitu std. Error of skewness yaitu 1.936, Std. Deviation 8.656, Signifikan hasil $0.000<0,005$ artinya ada pengaruh promkes terhadap peningkatan pengetahuan ibu tentang pemberian MP ASI.

\section{PEMBAHASAN}

Hasil dari karakteristik berdasarkan jumlah umur, pendidikan dan pekerjaan. Jumlah umur terbagi dua bagian yaitu pada umur 20-35 tahun berjumlah 17 responden (85\%). Sedangkan pada umur $>35$ tahun berjumlah 3 responden (15\%). Jumlah pendidikan terbagi menjadi empat bagian yaitu SD berjumlah 3 responden (15\%), SMP berjumlah 10 responden (50\%), SMA berjumlah 5 responden (25\%), S1 berjumlah 2 responden (10\%). Jumlah pekerjaan terbagi dua yaitu tidak bekerja 19 responden (95\%), dan yang bekerja 1 responden (5\%). faktor yang mempengaruhi pengetahuan antara lain: umur,pendidikan dan pekerjaan. Karena dengan bertambahnya umur seseorang akan mengalami perubahan aspek fisik dan psikologi atau mental. Pada aspek psikologi atau mental, taraf berpikir seseorang menjadi semakin matang dan dewasa. Pendidikan berarti bimbingan yang diberikan seseorang kepada orang lain agar dapat memahami sesuatu hal. Tidak dapat dipungkiri bahwa semakin tinggi pendidikan seseorang, semakin mudah pula mereka menerima informasi, dan pada akhirnya pengetahuan yang dimilikinya akan semakin banyak,

Hasil penelitian ini sejalan dengan penelitian Noviati ${ }^{5}$ menyatakan bahwa umur,pendidikan dan pekerjaan yang memiliki tingkat pengetahuan yang lebih tinggi sangat berpengaruh. Hal ini terbukti dari penelitian karakteristik umur 20-35 tahun lebih tinggi sama dengan peneliti lakukan, pendidikan yang lebih tinggi dilakukan penelitian terdahulu adalah SMA, berbanding terbalik dengan peneliti dapatkan pada hasil karakteristik pendidikan yang tertinggi adalah SD. Sedangkan karakteritik pekerjaan yang didapatkan pada peneliti terdahulu yaitu yang tidak bekerja lebih tinggi dibandingkan dengan yang bekerja. Hal ini sama dengan hasil karakteristik pekerjaan yang peneliti lakukan yaitu tidak bekerja lebih tinggi dibandingkan dengan yang bekerja

Hasil penelitian pengaruh promosi kesehatan terhadap pengetahuan ibu tentang pemberian MPASI yaitu memiliki signifikan hasil $0,000<0,005$ artinya ada pengaruh promosi kesehatan terhadap peningkatan pengetahuan ibu tentang pemberian MP-ASI. Hasil penelitian ini sejalan dengan Arini (2016) mimiliki pengaruh pelatihan pemberian MP-ASI kepada ibu dengan Baduta di kecamatan sukmajaya Depok terhadap pengetahuan dan perilaku pemberian MPASI dengan nilai $\mathrm{P}<0.05$.

promosi kesehatan adalah mempengaruhi, dan atau mengajak orang lain, baik individu, kelompok, atau masyarakat, meningkatkan perilaku masyarakat dan meningkatkan status kesehatan masyarakat.

Hasil penelitian ini sejalan dengan penelitian Supriati terdapat pengaruh penyuluhan dengan metode ceramah dan metode diskusi terhadap pengetahuan $(\mathrm{p}<0,00)$ dan sikap $(\mathrm{p}<0,001)$ ibu tentang pemberian makanan pendamping ASI. Hal ini sama dengan peneliti lakukan yaitu memiliki signifikan hasil 0,001 $<0,005$ artinya ada pengaruh promosi kesehatan terhadap peningkatan pengetahuan ibu tentang pemberian MP ASI. Hal ini didukung oleh jurnal penelitian USU-IR Home. Bahwa hasil penelitian menunjukkan terdapat pengaruh penyuluhan dengan metode ceramah dan metode diskusi terhadap pengetahuan ibu tentang pemberian makanan pendamping ASI

Sejalan dengan Hasil penelitian Wicaksono (2016) bahwa menunjukan hasil ada perbedaan yang siginfakan peningkatan nilai pengetahuan sebelum dan sesudah di berikan promosi kesehatan melalui Audio-Visual dengan nilai $\mathrm{P}=0,001$. Selaras juga dengan hasil penelitian 
Marfuah (2017) yaitu upaya peningkata pengetahuan ibu tentang MP-ASI dengan Edukasi Gizi melalui Booklet, mengalami peningkatan pengetahuan pola pemberian MP-ASI baik.

\section{KESIMPULAN}

Dari hasil penelitian dan pembahasan dapat disimpulkan distribusi frekuensi karakteristik responden terdiri dari karakteristik umur, pendidikan dan pekerjaan yang dapat dijabarkan sebagai berikut : karakteristik responden berdasarkan umur dalam penelitian menunjukkan responden terbanyak 17 responden $(85 \%)$. Karakteristik berdasarkan pendidikan responden yang terbanyak adalah SMP sebanyak 10 responden (50\%). Karakteristik berdasarkan pekerjaan yang terbanyak adalah yang tidak bekerja 19 responden (95\%). Ada pengaruh promkes terhadap peningkatan pengetahuan ibu tentang pemberian MP-ASI dengan nilai $\mathrm{P}=$ $0,000<0,005$.

\section{ACKNOWLEDGMENTS}

Penulis ingin berterimakasih kepada Universitas Nasional atas bantuan baik moril maupun materiil dan tentunya kepada semua pihak yang terkait dalam penelitian ini khususnya pihak Puskesmas Alusi Kecamatan Kormomolin Kepualian Tanimbar Maluku.

\section{DAFTAR PUSTAKA}

Dinas Kesehatan Kabupaten Kepulauan Tanimbar,2019. Profil Dinas Kesehatan Kabupaten Dwi Puji K, Hamam H, Bunga Astri P. (2016). Waktu Pemberian Makanan Pendamping ASI (MP-ASI) berhubungan dengan kejadian stunting anak usia 6-23 bulan di kecamatan sedayu, dalam Jurnal Gizi dan Dietetik Indonesia, Vol:4 No:2:105-111

Dewi M, Indah K, (2017). Upaya Peningkatan Pengetahuan Ibu tentan MP-ASI dengan Edukasi Gizi Melalui Booklet. Dalan Jurnal University Research Colloquium Hal : 273280

Eriza W, Trias M, (2017). Hubungan Pengetahuan Gizi dan pekerjaan Ibu terhadap pemberian MP-ASI Dini di Puskesam Telaga Biru Kota Pontianak, dalam Jurnal Amerta Nutrition Vol 1, No. 4 : 300-307

Firlia Ayu K, Nur Intan S, Ibnu Malkan B, (2016). Pengaruh Pelatihan MP-ASI Kepada Ibu dengan Anak Baduta di Kecamatan Sukmajaya Depok terhadap Pengetahuan dan perilaku pemberian MP-ASI dalam Jurnal Kedokteran dan Kesehatan, Vol:13 No:1 :80-89.

Fajri M, Nancy S.H, Nova H, (2018). Hubungan Antara Usia Pemberian Makanan Pendamping ASI (MP-ASI) Pertama Kali dengan Status Gizi Anak Usia 6-12 Bulan di Wilayah Kerja Puskesmas Kombos Kota Manado dalam Jurnal KESMAS, Vol:7 No:3

Lestari, D. (2012). Tingkat Pengetahuan Ibu Pada Anak Usia 6-24 bulan Di Desa Rembun Nogosari Boyolali. Surakarta:Skripsi STIKES Kusuma Husada

Notoatmodjo, S. (2012). Promosi Kesehatan dan Perilaku Kesehatan. Jakarta : Rineka Cipta

Notoatmodjo, S. (2012). Ilmu perilaku Kesehatan. Jakarta: Rineka Cipta

Rahmalia A, Shintya H, Hetty R, (2016). Faktor-Faktor yang berhubungan dengan pemberian MP-ASIpada Bayi Usia 0-6 Bulan di BPM Nurtila Palembang dalam Jurnal Kesehatan Vol: VII, No:2 : 260-265.

Riset Kesehatan Dasar. 2018. Rikesdas 2018 provinsi Maluku

USU-IR Home (2016). Efektifitas Promosi Kesehatan dengan Media Leaflet. Fakultas Kesehatan Universitas Sumatera Utara

WHO. (2011). Global strategy for infant and young child. http://www.who.int/nutrition/publicatio ns/infant feeding/9241562218

Waryana. (2010). Gizi Reproduksi. Yogyakarta : Pustaka RihamaKepulauan Tanimbar tahun 2019 
Wicaksono, D (2016), Pengaruh Media Audio-Visual. MP-ASI Terhadap Pengetahuan, Sikap dan Perilaku Ibu Baduta Di Puskesams Kelurahan Johar Baru dalam Jurnal ETHOS Vol:4 No.2: 291-298 